\title{
EVALUACIÓN DE LA CALIDAD DEL ENSILADO DE PASTO ESTRELLA AFRICANA (Cynodon nlemfluensis) MEZCLADO CON TRES DIFERENTES ADITIVOS ${ }^{1}$
}

\author{
Luis Pineda Cordero*, Pablo Chacón Hernández ${ }^{2 / *}$, Carlos Boschini Figueroa* \\ Palabras clave: Aditivos; conservación; melaza; maíz; citropulpa. \\ Keywords: Additives; preserving; molasses; corn; citrus pulp.
}

Recibido: $17 / 03 / 15$

Aceptado: 01/12/15

\begin{abstract}
RESUMEN
Se evaluaron las características del ensilado del pasto estrella africana (Cynodon nlemfluensis), y a la vez su proceso de fermentación al agregar la materia seca en niveles de $0 \%, 2 \%$ y $4 \%$ a los aditivos melaza, maíz molido o pulpa de cítricos deshidratada, sobre el forraje entero, recién cortado, vertido y compactado en bolsas plásticas disponibles comercialmente. El experimento se llevó a cabo en la Estación Experimental Alfredo Volio Mata, de la Universidad de Costa Rica, por medio de un diseño experimental factorial anidado. Se obtuvieron valores promedio de $23,68 \%, 22,21 \%$ y $23,52 \%$ de MS; $9,98 \%$, $9,89 \%$ y $10,58 \%$ de PC; $71,72 \%, 73,12 \%$ y $72,26 \%$ de FND; 44,95\%, 47,30\% y 46,73\% de FAD; $2,58 \%, 2,46 \%$ y $2,58 \%$ de EE; $10,08 \%, 10,31 \%$ y $10,34 \%$ de CEN para los ensilados con melaza, maíz molido y pulpa de cítricos deshidratada, respectivamente. Se observó pérdidas promedio de $14,97 \%, 16,84 \%$ y $14,82 \%$ de MS; $4,39 \%$, $5,24 \%$ y $3,82 \%$ de PC; $4,82 \%, 5,38 \%$ y $4,91 \%$ de FND; $3,68 \%, 3,90 \%$ y $3,34 \%$ de FAD; $2,46 \%$, $3,91 \%$ y $2,48 \%$ de EE; así como $3,96 \%, 4,02 \%$ y $3,32 \%$ de CEN, para los tratamientos de melaza, maíz y pulpa de cítricos deshidratada, respectivamente. Por último, no se encontró relación entre

1 Este proyecto fue financiado conjuntamente con fondos de la Cooperativa de Productores de Leche Dos Pinos y de la Universidad de Costa Rica. Proyecto 737-B1-074, inscrito en la Vicerrectoría de Investigación.
\end{abstract}

\begin{abstract}
Evaluation of african star grass (Cynodon nlemfluensis) silage quality when mixed with three different additives. The characteristics of african star grass (Cynodon nlemfluensis) silage, as well as its fermentation process when adding, at levels of $0 \%, 2 \%$ and $4 \%$ of the dry matter, molasses, ground corn or dehydrated citrus pulp, upon non-chopped, fresh forage, dumped and compacted on plastic bags commercially available. The experiment was carried on at the Universidad de Costa Rica's Alfredo Volio Mata Experimental Station, using a nested factorial experimental design. Average values of $23.68 \%, 22.21 \%$ and $23.52 \%$ of DM; $9.98 \%, 9.89 \%$ and $10.58 \%$ of CP; $71.72 \%, 73.12 \%$ and $72.26 \%$ of NDF; $44.95 \%, 47.30 \%$ and $46.73 \%$ of ADF; $2.58 \%, 2.46 \%$ and $2.58 \%$ of EE; $10.08 \%$, $10.31 \%$ and $10.34 \%$ of ASH were obtained when molasses, ground corn or dehydrated citrus pulp, respectively, were used. Also, average losses of $14.97 \%, 16.84 \%$ and $14.82 \%$ of DM; $4.39 \%$, $5.24 \%$ and $3.82 \%$ of CP; $4.82 \%, 5.38 \%$ and $4.91 \%$ of NDF; $3.68 \%, 3.90 \%$ and $3.34 \%$ of ADF; $2.46 \%$, $3.91 \%$ and $2.48 \%$ of EE; as well as $3.96 \%, 4.02 \%$ and $3.32 \%$ of $\mathrm{ASH}$ were found, respectively, on the molasses, ground corn and dehydrated
\end{abstract}

\footnotetext{
2 Autor para correspondencia. Correo electrónico: pablo.chacon@ucr.ac.cr

Universidad de Costa Rica, Facultad de Ciencias Agroalimentarias, Estación Experimental Alfredo Volio Mata, Costa Rica.
} 
el aditivo utilizado, o el nivel de inclusión de éste, sobre la producción de efluentes ( $\mathrm{p}>0,05)$, al tiempo que la evaluación organoléptica de todos los ensilados analizados fue excelente.

\section{INTRODUCCIÓN}

Las zonas tropicales, se caracterizan por presentar 2 estaciones muy bien definidas desde el punto de vista climatológico: una temporada lluviosa y otra poco lluviosa, situación que dificulta garantizar una producción constante de pastos a través del año. Este inconveniente se ha tratado de solucionar a través de diferentes mecanismos entre los cuáles, la elaboración de ensilados ocupa un lugar destacado (Luis et ál. 1991).

El éxito de un proceso de ensilaje radica en la capacidad de asegurar una adecuada fermentación del material almacenado, la cual depende tanto del tipo y la calidad del forraje como de la técnica empleada en todo el proceso de elaboración (Oude et ál. 2000). En el caso de los pastos tropicales que presentan valor de materia seca y carbohidratos solubles bajos, se pueden producir fermentaciones indeseables como resultado una mala conservación del material verde recién cortado (Mülhbach 2000).

Paralelamente, el uso de aditivos como práctica anexa al proceso de ensilaje, se realiza con el fin de favorecer el medio para una buena fermentación, que actue sobre la base de un contenido de materia seca entre $28 \%$ y $35 \%$, una cantidad de azúcares mínima de $8-12 \%$ y no presentar resistencia a la reducción de $\mathrm{pH}$ hasta valores de 3,8-4,2, características que permiten condiciones ideales para evitar la aparición de procesos que degraden y afecten la calidad final del material (Luis et ál. 1991, Bolsen et ál. 1996, Coan et ál. 2005, Castro et ál. 2006). citrus pulp treatments. No relationship was found between the additive used, or the inclusion level used, and effluent production from the silages ( $p>0.05)$. Finally, organoleptic evaluation of all analyzed silages were excellent.

Dentro de los diferentes aditivos utilizados, está la incorporación de ingredientes ricos en elementos fácilmente fermentables como la melaza, la cual puede disminuir rápidamente el pH del material así como la pérdida de nutrientes (Bolsen et ál. 1996), también se pueden utilizar granos como el maíz o subproductos industriales como la pulpa de cítricos deshidratada al proveer estos un sustrato fermentable, al mismo tiempo que trabajan como un absorbente del exceso de humedad en el forraje (Mülhbach 2000, Santos et ál. 2010), características que justifican su uso en forrajeras del género Cynodon dados sus bajos porcentajes de materia seca en el punto óptimo de corte (Coan et ál. 2005).

De esta forma el presente trabajo de investigación, tuvo como propósito evaluar las características del ensilado del pasto estrella africana (Cynodon nlemfluensis) así como su proceso de fermentación al agregar en 3 niveles ortogonales, 3 diferentes aditivos sobre el forraje entero recién cortado, vertido y compactado en bolsas plásticas convencionales disponibles comercialmente para este propósito.

\section{MATERIALES Y MÉTODOS}

\section{Ubicación}

El experimento se llevó a cabo en la Estación Experimental Alfredo Volio Mata, de la Universidad de Costa Rica, ubicada en El Alto de Ochomogo, distrito de San Rafael del cantón de 
La Unión en la provincia de Cartago, Costa Rica a 9 $55^{\prime} 10^{\prime \prime}$ latitud Norte y 8357'20" longitud Oeste y $1542 \mathrm{msnm}$, con una precipitación anual media de 1466 mm, distribuidos en la época lluviosa de mayo a noviembre; posee una humedad relativa media del $88 \%$ y una temperatura que va de los $13,5^{\circ} \mathrm{C}$ a los $22,2^{\circ} \mathrm{C}$ con un promedio anual de $17,9^{\circ} \mathrm{C}$ (Chacón y Boschini 2016).

\section{Manejo y cosecha de las pasturas}

La Estación Experimental Alfredo Volio M., se encuentra cultivada de pasto estrella africana (Cynodon nlemfluensis) en un suelo de origen volcánico, clasificado como Typic distrandepts, que se caracteriza por un buen drenaje y nivel de fertilidad medio (Vásquez 1982) por lo que el forraje destinado para el experimento no fue abonado con ningún tipo de fertilizante y fue cosechado a una edad de rebrote de 42 días por medio de una segadora acoplada a un tractor con una altura de corte a $5 \mathrm{~cm}$ sobre el nivel del suelo.

\section{Proceso de ensilaje}

\section{Acondicionamiento de las bolsas}

Para conservar el forraje se utilizaron bolsas comerciales de polietileno para la elaboración de ensilajes, que tienen dimensiones estándar de 0,18 milímetros de grosor, $91 \mathrm{~cm}$ de ancho, 125 $\mathrm{cm}$ de alto y una capacidad teórica calculada de 60 kilogramos de forraje verde. Antes de la preparación de los ensilajes cada bolsa fue acondicionada con un drenaje en el extremo inferior de la misma elaborado con un trozo de manguera plástica de $1 \mathrm{~cm}$ de diámetro interno y $30 \mathrm{~cm}$ de largo. De esa forma, se introdujeron $10 \mathrm{~cm}$ de la manguera a través de una perforación hecha a la bolsa sujetándola en la parte externa del plástico con $1,5 \mathrm{~m}$ de manila de nylon fuertemente arrollados. Posteriormente se recubrió con cinta adhesiva de tela la parte externa con un desagüe fijado totalmente con el intéres de dejar libres un total de $20 \mathrm{~cm}$ de la manguera para doblarla y contener los efluentes producidos durante el proceso de fermentación, pero con la posibilidad de extraerlos y cuantificarlos de forma sistemática durante el periodo experimental.

\section{Llenado de las bolsas}

Una vez acondicionada la manguera a las bolsas, se procedió con su llenado y a la vez se depositó en rollos, el forraje segado y recolectado en el campo sin ningún proceso de picado o marchitamiento previo. Las madejas de pasto fueron colocadas en las bolsas en capas de $20-25 \mathrm{~cm}$ de alto cada una para ser luego compactadas con los pies para asegurar la máxima extracción de aire. El proceso de llenado se continuó hasta que solo quedara plástico disponible para recoger los bordes de la bolsa.

\section{Aplicación de tratamientos}

Los aditivos seleccionados, fueron agregados de forma fraccionada luego de compactar cada una de las capas de forraje introducidas en las bolsas plásticas. Los mismos se asignaron a 3 tratamientos diferentes: melaza, maíz molido o pulpa de cítricos deshidratada cada uno en 3 niveles de adición ortogonales según un diseño experimental factorial anidado. Con base en análisis bromatológicos elaborados una semana antes del inicio del periodo experimental se determinaron los contenidos de materia seca, proteína cruda, fibra neutro detergente, fibra ácido detergente, lignina, hemicelulosa, celulosa, extracto etéreo, cenizas, proteína cruda incrustada en la fibra neutro detergente y los carbohidratos no fibrosos mediante la siguiente fórmula (NRC 2001):

$\mathrm{CNF}=100-((\mathrm{FND}-\mathrm{PCIFND})+\mathrm{PC}+\mathrm{EE}+\mathrm{CEN})$

donde:

$\mathrm{CNF}=$ carbohidratos no fibrosos, $\%$

FND = fibra neutro detergente, $\%$

PCIFND = proteína cruda incrustada en la fibra neutro detergente, $\%$

$\mathrm{PC}=$ proteína cruda, $\%$

$\mathrm{EE}=$ extracto etéreo, \%

$\mathrm{CEN}=$ cenizas, $\%$ 
Según los resultados obtenidos, se determinaron los niveles de inclusión 1, 2 y 3 de los aditivos, correspondientes a $0 \%, 2 \%$ y $4 \%$ de la materia seca, respectivamente. El nivel más bajo de melaza correspondió a una cantidad en la que se proporcionara un total carbohidratos no fibrosos basal de $10 \%$, mientras que para el maíz molido y la pulpa de cítricos deshidratada el nivel de inclusión menor de aditivo correspondió a un aumento de la materia seca en el ensilaje hasta alcanzar un mínimo de $20 \%$.

\section{Sellado de las bolsas de ensilaje}

Luego de agregados los aditivos, se procedió con el aislamiento del material con el cierre del plástico libre en la parte superior del empaque y a la vez se introdujo una manguera conectada a una bomba de vacío calibrada para ejercer 1 atmósfera de succión (equivalente a $-0,052 \mathrm{MPk},-38 \mathrm{~cm} \mathrm{Hg} \mathrm{o}-15$ psi) y así extraer todo el aire remanente en el material a ensilar. Al Final, después de la extracción de los gases, se amarró la bolsa con mecate de $3,2 \mathrm{~mm}$ de grosor mediante un doble nudo y luego se retorció el plástico de la bolsa sobrante hacia abajo para formar un moño sujetado con la misma cuerda para impedir un eventual ingreso de agua, polvo o insectos al interior.

\section{Diseño experimental y muestreo}

Al momento de la elaboración de los ensilajes, se tomaron muestras del forraje en fresco las cuales fueron enviadas al laboratorio para el análisis de su composición nutricional; por su parte, la composición de los aditivos fue tomada según la información comercial disponible de cada uno.

Se aplicó un diseño factorial anidado (Steel y Torrie 1988) con 9 tratamientos y 4 repeticiones. Los factores correspondieron a los 3 aditivos empleados en los 3 niveles de inclusión determinados. El periodo experimental fue de 63 días, durante los cuales se realizó la recolección de efluentes cada 7 días. Al finalizar el periodo experimental, las bolsas fueron pesadas, abiertas y se procedió inmediatamente a realizar evaluación sensorial (olor, color y textura) con una modificación de la metodología descrita por Betancourt et ál. (2005); además, se recolectó una muestra de cada bolsa para efectuar los análisis de laboratorio correspondientes.

\section{Análisis de laboratorio}

A todas las muestras recolectadas tanto de forraje como de ensilado, se les realizaron evaluaciones de composición nutricional en el Laboratorio de Bromatología de la Estación Experimental "Alfredo Volio Mata", donde se determinó el contenido de materia seca (MS) en una estufa a $105^{\circ} \mathrm{C}$, la proteína cruda (PC) por el método de Kjeldahl, el extracto etéreo (EE), las cenizas totales (CEN) según los métodos establecidos por la A.O.A.C. (2000), la fibra neutro detergente (FND), la fibra ácido detergente (FAD) y la lignina (LIG) por el método de Goering y Van-Soest (1970) y Van-Soest et ál. (1991); por último, los valores de hemicelulosa (HEMI) y celulosa (CEL) se estimaron por diferencia de las fracciones correspondientes. Se determinó además el pH con el uso de un potenciómetro marca Daigger, modelo 6173pH, serie JCO2826.

\section{Análisis de resultados}

Los valores bromatológicos del forraje inicial en mezcla con los aditivos, así como los contenidos nutricionales al finalizar el experimento fueron sometidos a un análisis de varianza con el PROC ANOVA del paquete estadístico S.A.S. (1985). Aquellas variables que mostraron diferencias importantes entre 
medias, fueron sometidas a la prueba de Duncan para su segregación estadística. Mediante este mismo procedimiento se cuantificó la variación de pérdidas ocurridas durante el proceso de fermentación. El comportamiento de la producción acumulativa de efluentes se analizó por medio del PROC REG y se determinó la regresión de mejor ajuste para cada aditivo y nivel de este.

\section{RESULTADOS Y DISCUSIÓN}

\section{Composición nutricional de los materiales antes del proceso de ensilaje}

Los resultados obtenidos de composición nutricional tanto del pasto estrella africana como de los aditivos utilizados se muestran en el Cuadro 1.

Cuadro 1. Composición bromatológica del pasto estrella africana (Cynodon nlemfluensis), pulpa de cítricos deshidratada, maíz molido y melaza.

\begin{tabular}{|c|c|c|c|c|c|c|c|c|}
\hline Trat & Nivel & $\begin{array}{c}\text { Peso inicial, } \\
\text { kg }\end{array}$ & DS & Peso final, $\mathrm{kg}$ & DS & $\begin{array}{l}\text { Dif de peso, } \\
\qquad \mathrm{kg}\end{array}$ & DS & $\begin{array}{c}\text { Dif de peso, } \\
\%\end{array}$ \\
\hline \multirow[t]{4}{*}{ Melaza } & 1 & 41,13 & 0,85 & 40,25 & 0,64 & 0,88 & 0,25 & 2,14 \\
\hline & 2 & 42,88 & 2,59 & 42,50 & 2,67 & 0,38 & 0,24 & 0,89 \\
\hline & 3 & 41,63 & 0,94 & 41,50 & 1,35 & 0,13 & 0,41 & 0,31 \\
\hline & Prom & 41,88 & 1,69 & 41,42 & 1,87 & 0,46 & 0,34 & 1,10 \\
\hline \multirow[t]{4}{*}{ Maíz } & 1 & 42,00 & 1,77 & 41,25 & 1,70 & 0,75 & 0,28 & 1,79 \\
\hline & 2 & 42,50 & 2,44 & 40,50 & 2,39 & 2,00 & 0,28 & 4,71 \\
\hline & 3 & 41,00 & 0,41 & 40,25 & 0,81 & 0,75 & 0,40 & 1,83 \\
\hline & Prom & 41,83 & 1,72 & 41,17 & 1,68 & 0,66 & 0,32 & 1,58 \\
\hline Pulpa de cítricos & 1 & 43,00 & 1,77 & 42,25 & 1,55 & 0,75 & 0,28 & 1,74 \\
\hline \multirow[t]{3}{*}{ deshidratada } & 2 & 41,25 & 0,64 & 40,63 & 0,75 & 0,62 & 0,25 & 1,50 \\
\hline & 3 & 41,25 & 0,95 & 40,88 & 0,75 & 0,37 & 0,47 & 0,90 \\
\hline & Prom & 41,83 & 1,40 & 41,25 & 1,23 & 0,58 & 0,32 & 1,39 \\
\hline
\end{tabular}

$\mathrm{a}, \mathrm{b}, \mathrm{c}$ marcan diferencias $(\mathrm{p}<0,05)$ estadísticas entre tratamientos.

\section{Materia seca y componentes de la pared celular}

El contenido de materia seca del forraje utilizado fue superior al mínimo recomendado de $30 \%$ para la elaboración de ensilajes (Bumbieris et ál. 2009); además, el valor es cercano al 30,5\% reportado por Sánchez et ál. (1998) en pasto estrella africana y Dean et ál. (2005) para el pasto bermuda (Cynodon dactylon). Vendramini et ál. (2010), informan para el pasto estrella, valores de 
$71,7 \%$ y $40,5 \%$ para la FND y la FAD respectivamente, valores similares a los encontrados en el presente experimento (Cuadro 1), con la cantidad de FAD presente en el material, el máximo permitido para que no exista una reducción en el consumo voluntario de forraje (Moreira et ál. 2003).

Los contenidos de HEMI encontrados, coinciden con los valores dados por Herrera et ál. (2009), quienes encontraron un 30,86\% del componente en muestras de pasto estrella africana. Al mismo tiempo los valores de celulosa en el presente experimento, fueron menores a lo descrito por Dean et ál. (2005) quienes indican una concentración de $35,00 \%$.

\section{Proteína cruda}

Los valores en el Cuadro 1 son similares a los que reportan González et ál. (1996), quienes encontraron un $10 \%$ de PC en el mismo forraje, que representan valores mayores al mínimo recomendado de $7 \%$ para mantener un consumo y digestibilidad ruminal del alimento óptimos (Sánchez et ál. 1998). Aunque alrededor de un $45,7 \%$ del total de proteína corresponde a PCIFND, lo cual podría reducir la cantidad de nitrógeno disponible para los microorganismos ruminales, al ser éste utilizado de forma más lenta por su dependencia con la degradación de la fracción fibrosa en el forraje (Moreira et ál. 2003).

\section{Extracto etéreo}

El valor obtenido de 2,13\% en las pruebas de determinación del EE, corresponden a valores un poco más altos a los conseguidos en pasto estrella por Bumbieris et ál. (2009) ya que dichos autores presentan una concentración correspondiente a un $1,21 \%$.

\section{Lignina y cenizas}

Los valores de cenizas presentaron comportamiento similar si se comparan con las cantidades reportadas por Dean et ál. (2005) de 5,7\% de la MS en pasto bermuda con 35 días de crecimiento. Conjuntamente, los valores de lignina son evidentemente menores al $10,64 \%$ reportado por Herrera et ál. (2009) lo cual puede deberse a la diferencia de edades de cosecha ya que en el presente análisis el forraje se cosechó con 18 días menos de rebrote. Igualmente el valor de LIG es menor al 8,47\% determinado por Rodríguez y Elizondo (2012) en estrella africana con 50 días de crecimiento.

\section{Carbohidratos no fibrosos}

El 11,5\% de CNF conseguido por Sánchez et ál. (1998) para pasto estrella, durante la época semiseca en la zona norte de Costa Rica, es apenas más bajo que en las muestras analizadas, y respalda la necesidad planteada por Umaña et ál. (1991) de utilizar aditivos que permitan mejorar el patrón fermentativo de forrajes pertenecientes al género Cynodon.

\section{Composición nutricional del ensilado de pasto estrella africana (Cynodon nlemfluensis) según el tipo y nivel de inclusión de aditivo}

Se encontraron diferencias estadísticamente significativas $(\mathrm{p}<0,05)$ para todas las fracciones consideradas en los análisis bromatológicos efectuados al forraje inicial mezclado con melaza, maíz molido o pulpa de cítricos deshidratada (Cuadro 2). A pesar de que estadísticamente hubo diferencias, la magnitud de los residuos, entre tratamientos no supera al $1 \%$ para los componentes analizados, excepto para la concentración de FND dónde la diferencia máxima se produjo entre la pulpa de cítricos deshidratada y la melaza, probablemente debido a la variación entre la composición de ambos productos. Asimismo, el uso de pulpa de cítricos deshidratada fue el aditivo que según los análisis de varianza, elevó en mayor proporción la cantidad de PC, FND, FAD, HEMI, CEL y LIG; mientras que la melaza fue la que porcentajes más bajos presentó $(\mathrm{p}<0,05)$. 


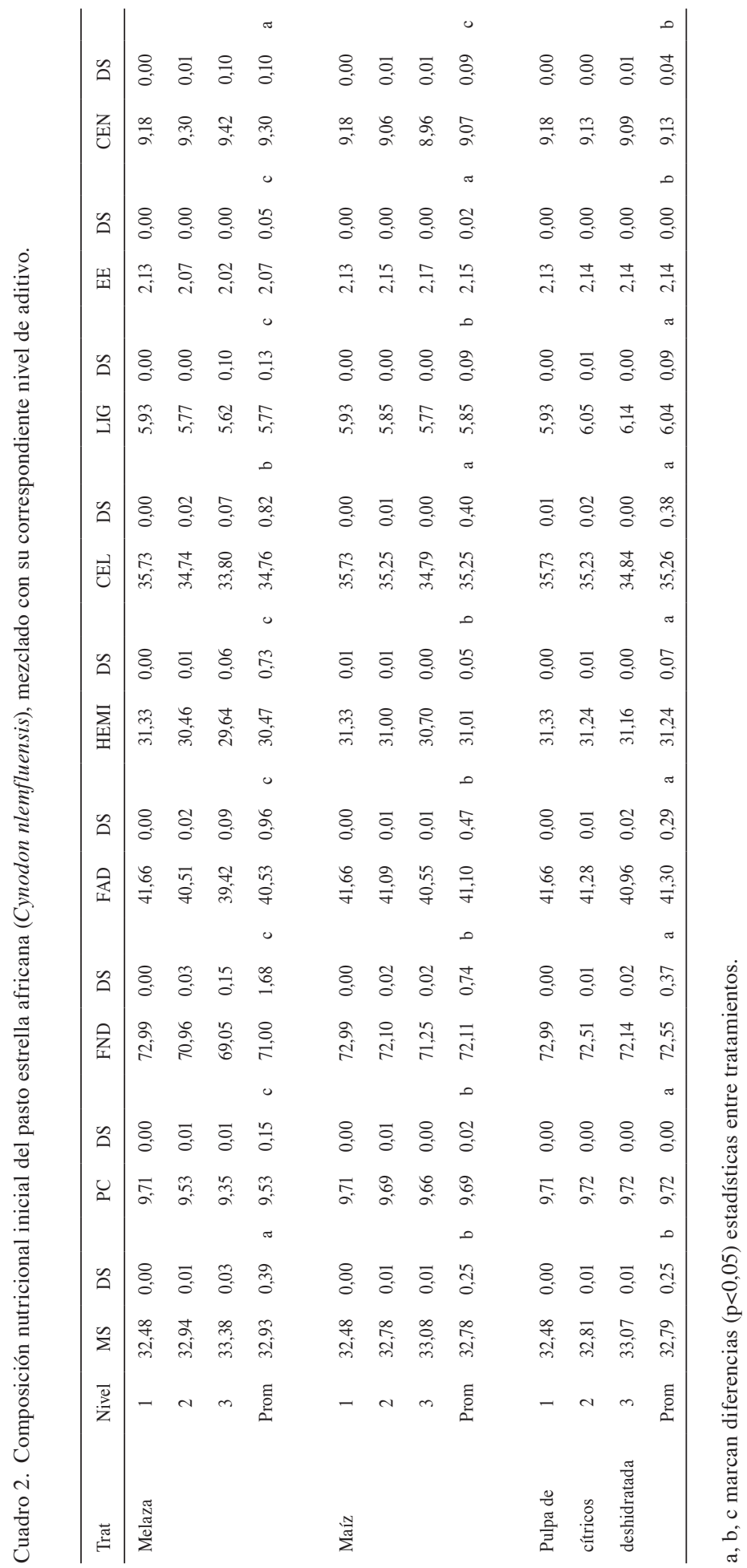


En los ensilados no fue posible realizar una segregación de medias según el tratamiento desde el punto de vista estadístico para la mayoría de las fracciones analizadas en el laboratorio ( $p>0,05)$; únicamente hubo diferencias entre aditivos para los contenidos promedio de MS, FAD y CEL ( $\mathrm{p}<0,05$; Cuadro 3). Esta similitud en la composición nutricional de los diferentes ensilados estudiados independientemente del aditivo añadido, sugiere una estabilización cualitativa del material fermentado asignable a que los materiales alcanzan un valor de $\mathrm{a}_{\mathrm{w}}$ menor a 0,94 que no permite la supervivencia y actividad de bacterias acido lácticas que fermentan el forraje (Tohno et ál. 2012). En el caso de la FAD y la CEL, el valor fue menor en los tratamientos que incluían melaza debido a la ausencia de esas fracciones en ese aditivo (Cuadro 1), mientras que el maíz molido y la pulpa de cítricos deshidratada presentaron cantidades similares estadísticamente $(\mathrm{p}<0,05)$.

\section{Materia seca y componentes de la pared celular}

Los porcentajes de MS obtenidos en el ensilado son menores que en el material analizado antes del proceso de conservación para todos los tratamientos, lo cual puede deberse tanto a pérdidas en los efluentes producidos, como al procedimiento de determinación empleado en el cuál no se contabiliza la cantidad de compuestos volátiles presentes (Miller et ál. 1966). Por otra parte, el valor de MS señalado para el ensilado obtenido al mezclar el pasto estrella con maíz molido (Cuadro 3), es muy similar al determinado por Miller et ál. (1966), quienes reportan un $32,8 \%$ al mezclar pasto Bermuda con un $4,5 \%$ de maíz molido; mientras que el valor obtenido al utilizar pulpa de cítricos deshidratada es menor al $37,70 \%$ encontrado en la literatura para pasto Tifton 85 (Coan et ál. 2005); esta diferencia puede ser debido a la variedad de pasto utilizada en ambos ensayos o al mayor porcentaje de inclusión de aditivo ya que en dicha prueba los autores utilizaron un nivel de 5\%. Además, si se comparan los resultados alcanzados en este experimento, la magnitud de MS obtenida en los tratamientos analizados es similar a la obtenida con aditivos enzimo-bacterianos si se compara con el 33,85\% reportado por Bumbieris et ál. (2009), con una dosis de agregado comercial de $0,015 \%$.

El valor de FND mostrado en el Cuadro 3, es similar al $72,8 \%$ reportado por Coan et ál. (2005), aunque es un poco menor a lo determinado por Quaresma et ál. (2010), quienes determinaron un promedio de $75,60 \%$ en pasto estrella africana blanca (Cynodon plectostachyus) pre marchitado, proceso que incrementa el contenido de dicho componente en el ensilado final a causa de la eliminación de compuestos solubles durante el proceso de pre secado (Quaresma et ál. 2010) y el de fermentación (Bumbieris et ál. 2009), lo que explica la diferencia encontrada. Mientras tanto, en FAD Bumbieris et ál. (2009) reportan porcentajes de $43,88 \%$ sin aplicación de aditivos y $43,89 \%$ con la aplicación de aditivos enzimobacterianos a ensilaje de pasto estrella, valores que son cercanos a lo encontrado, observación que también aplica para el 40,6\% reportado por Evangelista et ál. (2000) con estrella roja (Cynodon nlemfluensis Vanderyst.) pre marchitada durante una hora antes de ensilar.

En el caso de la HEMI, las cantidades determinadas y mostradas en el Cuadro 3, presentan valores levemente más bajos que la concentración promedio de 29,9\% en los ensilados de pasto estrella africana blanca evaluados por Quaresma et ál. (2010). De esta manera, la cantidad de celulosa promedio determinada en el presente experimento para los diferentes tratamientos estudiados, es levemente más alta al 37,17\% que reportan Castro et ál. (2006) en Tifton 85 (Cynodon spp.) ensilado con un 35\% de MS. 


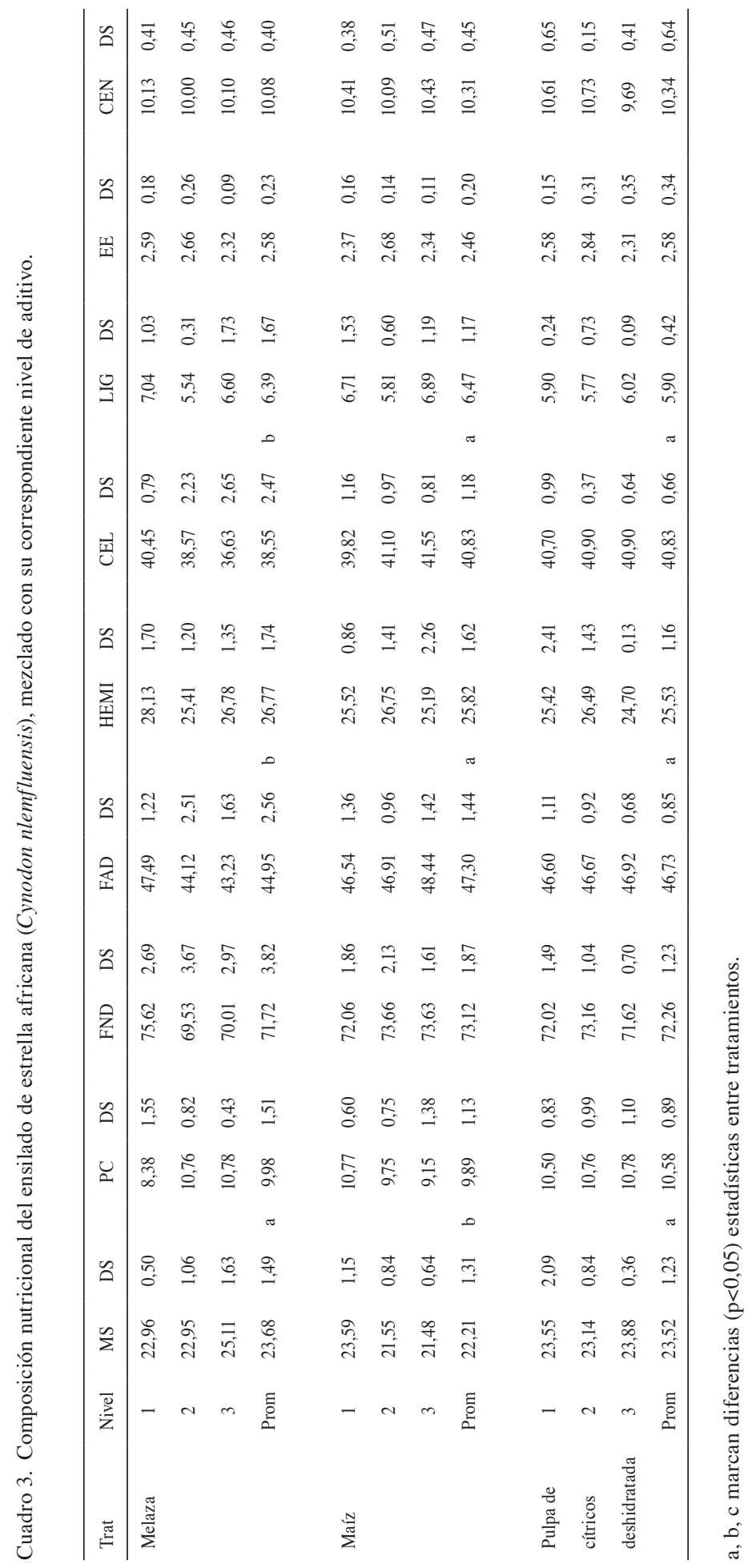




\section{Proteína cruda}

Los contenidos de PC obtenidos en el ensilado final no presentaron variación significativa entre los aditivos utilizados, por ser estos valores cercanos a lo presentado para pasto estrella por Quaresma et ál. (2010), con material premarchitado (9,87\% de Proteína bruta) y por Bumbieris et ál. (2009) al conservar el pasto con un aditivo enzimo-bacteriano $(10,00 \%$ de Proteína bruta) pero menores que lo reportado para pasto bermuda (Cynodon dactylon) por Miller et ál. (1963) y Miller et ál. (1966) $(14,2 \%$ y 13,4\%, respectivamente) ambos con un 4,5\% de maíz molido como aditivo, diferencia que probablemente se deba al contenido inicial de proteína cruda diferente en ambas variedades de forraje, no debido a procesos de desaminación al verse estos disminuidos por descensos rápidos en el pH (Makoni et ál. 1997) que inhiben el desarrollo de bacterias clostrídicas en el ensilaje (Luis y Ramírez 1985), situación que se debió ver favorecida con la inclusión de los aditivos utilizados.

\section{Extracto etéreo}

A su vez, los porcentajes de EE en los ensilados analizados no presentaron distanciamientos significativos entre tratamientos. Dichos resultados fueron considerablemente menores a los valores reportados por Castro et ál. (2006), quienes encontraron valores de $11,6 \%$ para pasto Tifton 85 ensilado durante 90 días sin el uso de aditivos, discrepancia que podría explicarse por el menor tiempo de conservación empleado en este ensayo, ya que según indican los autores mencionados, dicha fracción se incrementa conforme aumenta el almacenamiento; otra explicación para esta diferencia puede ser un contenido inicial del EE ampliamente mayor al del pasto estrella analizado en el presente experimento. Asimismo, a pesar de las diferencias respecto a la literatura, las proporciones determinadas para este componente son superiores a la base de $2,1 \%$ indicada por
Santos et ál. (2010) en ensilados de buena calidad elaborados con forrajeras tropicales.

\section{Lignina y cenizas}

En concordancia con lo encontrado (Cuadro 3), Castro et ál. (2006) evaluaron ensilados de pasto Tifton 85 con y sin la aplicación de aditivos enzimo-bacterianos y ácido propiónico buffer y no encontraron diferencias estadísticamente significativas para el contenido de lignina entre tratamientos luego de un periodo de fermentación de 32 días $(6,67 \%$ y $6,59 \%$ de lignina en el ensilado con y sin la adición de aditivo enzimo-bacteriano, respectivamente) que además presentaron los valores para este componente, cercanos a los aquí presentados.

Por otra parte, los contenidos de cenizas encontrados (Cuadro 3), a pesar de no presentar diferencias significativas entre tratamientos $(p>0,05)$, son considerablemente mayores a lo reportado por Dean et ál. (2005), quienes encontraron valores que rondan los 5-6\% de la materia seca en ensilados de pasto bermuda tratado con diversas enzimas fibrolíticas; el mismo comportamiento se observa con lo reportado por Evangelista et ál. (2000), los cuales informan de valores todavía más bajos al utilizar pasto estrella roja premarchitado (2\% de minerales en base seca). Las anteriores diferencias podrían ser debidas a la composición mineral normal de las variedades analizadas en los ensayos.

\section{Pérdidas de nutrientes durante el proceso de ensilaje de pasto estrella (Cynodon nlemfluensis) según el tipo y nivel de inclusión de aditivo}

Los ensilajes elaborados fueron pesados al momento de su elaboración y cuando fueron abiertos (Cuadro 4), con el fin de determinar la cantidad de pérdidas producidas durante el proceso de fermentación. Según la prueba de Duncan, no hubo diferencias estadísticamente significativas $(p>0,05)$ en los pesos de los ensilados según el nivel de aditivo empleado, ni entre éstos. 
Cuadro 4. Peso inicial y final del pasto estrella africana (Cynodon nlemfluensis) ensilado con su respectivo nivel de aditivo, en base fresca.

\begin{tabular}{|c|c|c|c|c|c|}
\hline Tratamiento & Nivel aditivo & $\begin{array}{l}\text { Peso inicial } \\
\quad(\mathrm{kg})\end{array}$ & $\begin{array}{l}\text { Peso final } \\
\quad(\mathrm{kg})\end{array}$ & $\begin{array}{l}\text { Diferencia de peso } \\
\qquad(\mathrm{kg})\end{array}$ & $\begin{array}{c}\text { Diferencia de peso } \\
\text { (\%) }\end{array}$ \\
\hline \multirow{4}{*}{ Melaza } & 1 & 41,13 & 40,25 & 0,88 & 2,14 \\
\hline & 2 & 42,88 & 42,5 & 0,38 & 0,89 \\
\hline & 3 & 41,63 & 41,5 & 0,13 & 0,31 \\
\hline & Promedio & 41,88 & 41,42 & 0,46 & 1,1 \\
\hline \multirow{4}{*}{ Maíz molido } & 1 & 42 & 41,25 & 0,75 & 1,79 \\
\hline & 2 & 42,5 & 40,5 & 2 & 4,71 \\
\hline & 3 & 41 & 40,25 & 0,75 & 1,83 \\
\hline & Promedio & 41,83 & 41,17 & 0,66 & 1,58 \\
\hline \multirow{4}{*}{$\begin{array}{l}\text { Pulpa de cítricos } \\
\text { deshidratada }\end{array}$} & 1 & 43 & 42,25 & 0,75 & 1,74 \\
\hline & 2 & 41,25 & 40,63 & 0,62 & 1,5 \\
\hline & 3 & 41,25 & 40,88 & 0,37 & 0,9 \\
\hline & Promedio & 41,83 & 41,25 & 0,58 & 1,39 \\
\hline
\end{tabular}

Según el Cuadro 5, el comportamiento estadístico para las pérdidas de MS, EE, PC, HEMI, FAD, LIG y CEN según el aditivo empleado, es inverso a la cantidad de nutrientes finales en los forrajes ensilados (Cuadro 3) por ser mayores los valores de cada fracción para los aditivos donde la pérdida de dicho componente fue menor. Debido a que el maíz molido pierde CEL y FND en mayor cantidad que la pulpa de cítricos deshidratada $(0,56 \%$ y $0,79 \%$, respectivamente), la cantidad final de ambos componentes en el ensilado es menor con el uso del primero ( $\mathrm{p}<0,05$; Cuadro 3 ) por ser el comportamiento de la melaza intermedio al de los 2 anteriores a causa de la composición química de la misma. 


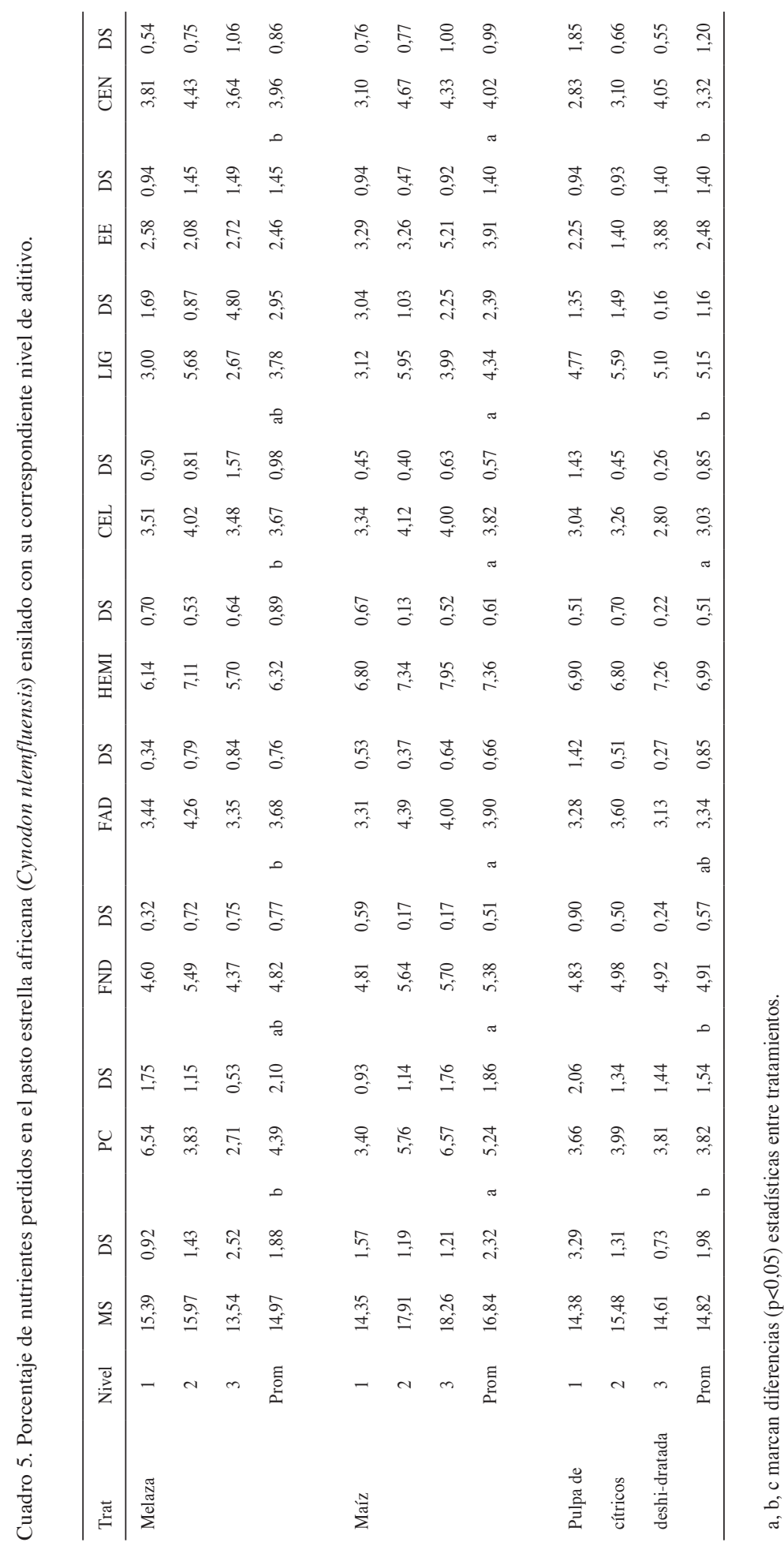

Agronomía Costarricense 40(1): 11-27. ISSN:0377-9424 / 2016 


\section{Pérdidas de materia seca}

Las mayores pérdidas de MS observadas, se produjeron al agregar maíz molido al forraje, que correspondieron a una disminución total de un $16,84 \%$ con respecto al material inicial ( $\mathrm{p}<0,05$; Cuadro 5); mientras que la melaza y la pulpa de cítricos deshidratada fueron estadísticamente similares $(14,97 \%$ y $14,82 \%$, respectivamente; $\mathrm{p}<0,05)$. Estos valores son similares a las pérdidas promedio reportadas por Quaresma et ál. (2010), quienes al ensilar estrella africana blanca, recuperaron un $86,98 \%$ de la MS ensilada; sin embargo, difiere de lo determinado por Dean et ál. (2005), para quienes el mayor porcentaje de MS pérdida fue de 9,5\%; no obstante, ésta diferencia probablemente es debida al uso de especies de forraje diferentes en ambos experimentos (Quaresma et ál. 2010), o al método utilizado en laboratorio para establecer el contenido de MS en las muestras analizadas (Miller et ál. 1966), ambos de importancia significativa. Conjuntamente, Dean et ál. (2005) determinaron variación en la pérdida de materia seca según el aditivo aplicado al forraje, similar a lo presentado en el Cuadro 5.

\section{Pérdidas de proteína cruda}

La variación en las pérdidas de PC generadas, pueden ser por el tiempo de almacenamiento del ensilaje ya que los contenidos tienden a disminuir conforme se aumenta la edad de cosecha (Miller et ál. 1963) y el tiempo de almacenamiento del material ensilado (Umaña et ál. 1991, Castro et ál. 2006). Según Sibanda et ál. (1997), el uso de maíz molido como aditivo de ensilajes, tiende a retener el contenido total de nitrógeno en los ensilajes, situación opuesta a lo determinado en el presente ensayo dónde el maíz generó el mayor porcentaje de pérdidas de PC $(5,24 \%$ contra $4,39 \%$ de la melaza y $3,82 \%$ de la pulpa de cítricos deshidratada). Además esos autores señalaron que la aplicación de melaza a los ensilajes reduce el contenido de nitrógeno amoniacal, disminuyendo las pérdidas de nitrógeno al ambiente al producir una mejor conservación del material; situación que podría explicar porque las menores pérdidas de PC se produjeron al agregar este aditivo al forraje (Cuadro 5).

\section{Pérdidas de fibra}

A pesar de la pérdida de las distintas fracciones de la fibra, una reducción en el porcentaje de FND y FAD es deseable para garantizar una buena calidad del ensilado producido, ya que esto acorta el tiempo necesario para la digestión del alimento en los rumiantes; de forma tal, que al aumentar la tasa de paso del alimento por el tracto digestivo se amplifique el consumo de alimento diario realizado por el animal (Pereira et ál. 1999). Además, es posible que se genere pérdida de HEMI por los pocos carbohidratos fácilmente fermentables en el forraje, ya que las bacterias ácido lácticas deben utilizar los azúcares contenidos en esta fracción con el fin de disminuir el $\mathrm{pH}$ y que el proceso de conservación se de en forma satisfactoria (Bolsen et ál. 1996).

\section{Producción de efluentes}

Los únicos tratamientos analizados que produjeron efluentes correspondieron al de mayor nivel de inclusión de melaza (4\%), asî como la adición de un $2 \%$ y $4 \%$ de maíz molido al ensilaje, aunque la información recolectada muestra que el tiempo de almacenamiento no permite predecir la cantidad de efluente producida por el silo (Cuadro 6). Además, el comportamiento observado en esos ensilajes, es inverso a lo que mencionan Martínez et ál. (1999), quienes indican que la producción de lixiviados sería ínfima cuando el contenido inicial de MS del material ensilado es de $25 \%$ o más, pero concuerdan con lo descrito por Miller y Clifton (1965), que reportan incremento en éstos al utilizar melaza, y ningún efecto significativo en la reducción con la adición de maíz molido en porcentajes bajos de inclusión a ensilajes de forrajeras altas en humedad. 
Cuadro 6. Predicción de los kilogramos de efluente producidos (Y) según el tiempo de almacenamiento del ensilaje de pasto estrella africana (Cynodon nlemfluensis) en días (X).

\begin{tabular}{llc}
\hline Tratamiento & Ecuación de regresión & $\mathrm{R}^{2}$ \\
\hline $4 \%$ de melaza & $\mathrm{Y}=-1,1206+0,71109 \mathrm{X}-0,0051 \mathrm{X}^{2}$ & 0,08 \\
$2 \%$ de maíz molido & $\mathrm{Y}=0,3667-0,0670 \mathrm{X}+0,0017 \mathrm{X}^{2}$ & 0,22 \\
$4 \%$ de maíz molido & $\mathrm{Y}=0,6746-0,1286 \mathrm{X}+0,0032 \mathrm{X}^{2}$ & 0,22 \\
\hline
\end{tabular}

La problemática de la producción de efluentes en los ensilajes, radica en la pérdida de componentes solubles (principalmente carbohidratos), reduciéndose entonces los sustratos disponibles para la fermentación aspecto que dificulta la disminución del $\mathrm{pH}$ (Miller y Clifton 1965, Fransen y Strubi 1998, Martínez et ál. 1999). Esa pérdida de carbohidratos en los lixiviados del ensilaje; como ya fue mencionado, puede llevar a una disminución en el contenido de HEMI al ser utilizada esta como fuente de energía por las bacterias en el proceso de fermentación lo que llevaría a una reducción de la calidad nutritiva del material conservado (Bolsen et ál. 1996). El otro problema generado por la producción de efluentes corresponde al poder contaminante de los mismos, como respuesta a la alta demanda química y biológica de oxígeno (DQO y DBO, respectivamente), lo que los convierten en amenazas contra la calidad del agua y la vida acuática (Fransen y Strubi 1998, Martínez et ál. 1998, Martínez et ál. 1999).

pH y evaluación sensorial del ensilado de pasto estrella (Cynodon nlemfluensis) según el tipo y nivel de inclusión de aditivo

Los valores de $\mathrm{pH}$ determinados (Cuadro 7), son superiores al 4,5 recomendado por Fransen

Cuadro 7. Valor de pH y evaluación organoléptica del ensilado de pasto estrella africana (Cynodon nlemfluensis) con su respectivo nivel de aditivo.

\begin{tabular}{|c|c|c|c|c|c|c|c|}
\hline \multirow{2}{*}{ Trat } & \multirow{2}{*}{ Nivel } & \multirow{2}{*}{$\mathrm{pH}^{/ 4}$} & \multirow{2}{*}{ DS } & & \multicolumn{3}{|c|}{ Puntaje } \\
\hline & & & & & Olor $^{\prime 1}$ & Color $^{12}$ & Textura $^{13}$ \\
\hline \multirow[t]{4}{*}{ Melaza } & 1 & 5,52 & 0,09 & & 4 & 4 & 4 \\
\hline & 2 & 4,57 & 0,05 & & 4 & 4 & 4 \\
\hline & 3 & 4,62 & 0,12 & & 4 & 4 & 4 \\
\hline & Prom & 4,90 & 0,46 & $\mathrm{~b}$ & 4 & 4 & 4 \\
\hline \multirow[t]{4}{*}{ Maíz } & 1 & 5,25 & 0,13 & & 4 & 4 & 4 \\
\hline & 2 & 4,85 & 0,19 & & 4 & 4 & 4 \\
\hline & 3 & 5,10 & 0,41 & & 4 & 4 & 4 \\
\hline & Prom & 5,06 & 0,22 & $\mathrm{a}$ & 4 & 4 & 4 \\
\hline Pulpa de & 1 & 5,15 & 0,06 & & 4 & 4 & 4 \\
\hline cítricos & 2 & 5,40 & 0,29 & & 4 & 4 & 4 \\
\hline \multirow[t]{2}{*}{ deshidratada } & 3 & 4,72 & 0,19 & & 4 & 4 & 4 \\
\hline & Prom & 5,09 & 0,34 & $\mathrm{a}$ & 4 & 4 & 4 \\
\hline
\end{tabular}

${ }^{1 /}$ Escala de olor: 4 agradable, 3 ligeramente olor a moho, 2 moderado olor a moho, 1 fuerte olor a moho, 0 fétido.

${ }^{2 /}$ Escala de color: 4 verde pálido, 3 verde musgo, 2 verde oscuro, 1 verde pardo, 0 pardo.

${ }^{3 / E s c a l a}$ de textura: 4 firme y consistente, 3 consistente, 2 medio, 1 suave, 0 con mucílago.

4/a, b, c marcan diferencias $(\mathrm{p}<0,05)$ estadísticas entre tratamientos. 
y Strubi (1998) para ensilajes menos propensos a deterioro; aunque según Evangelista et ál. (2000), forrajes conservados del género Cynodon, suelen presentar valores de $\mathrm{pH}$ que varían dentro de un rango que va de 4,5 a 5,3; lo que resulta similar a lo determinado en los ensayos acá descritos. Ese valor de $\mathrm{pH}$ mayor puede deberse al contenido de MS el cual ha sido demostrado que tiende a incrementar el $\mathrm{pH}$ del ensilado final, al afectar la producción de ácido láctico por las bacterias encargadas de fermentar el forraje (Umaña et ál. 1991, Evangelista et ál. 2000, Castro et ál. 2006); o por liberación de nitrógeno amoniacal (Cuadro 5) que actúa como buffer y contrarresta la producción de ácidos orgánicos (Miller et ál. 1966, Makoni et ál. 1997, Santos et ál. 2000).

La evaluación sensorial realizada, indicó una adecuada fermentación del pasto estrella africana, al presentar todas las características evaluadas puntuaciones excelentes sin importar el tipo de aditivo o el nivel de inclusión del mismo. Este excelente desempeño del material ensilado, desde el punto de vista sensorial, puede explicarse gracias al aporte de carbohidratos fácilmente fermentables hecho por los aditivos utilizados (Qamar 2009, Maza et ál. 2011) lo cual aumenta la posibilidad de conservación del forraje estudiado, similares observaciones describen Sibanda et ál. (1997) al probar melaza y maíz molido como aditivos en ensilajes de pasto estrella mezclada con Desmodium uncinatum y López et ál. (2009) con melaza y pulpa de cítricos deshidratada en ensilado de rastrojo de piña.

\section{LITERATURA CITADA}

A.O.A.C. 2000. Association of Official Analysis Chemistry. Official methods of analysis. $17^{\text {th }}$ Ed. Washington DC., Estados Unidos. 2590 p.

BETANCOURT M., GONZÁLEZ I., MARTÍNEZ M. 2005. Evaluación de la calidad de los ensilajes. Revista Digital CENIAP HOY 8:1-5.

BOLSEN K.K., ASHBELL G., WIENBERG Z.G. 1996. Silage fermentation and silage additives. Asian-Aust Journal of Animal Science 9(5):483-493.

BUMBIERIS V.H., JOBIM C.C., CALIXTO M., CECATO U. 2009. Composição química e digestibilidade em ovinos da grama estrela ensilada com diferentes aditivos. Ciênc agrotec, Lavras 33(5):1408-1414.

CASTRO F.G.F., NUSSIO L.G., MALUF C., CAMPOS F.P.D., COELHO R.M., MARI L.J., TOLEDO P.D.A. 2006. Características de fermentação e composição químico-bromatológica de silagens de capim-Tifton 85 confeccionadas com cinco teores de matéria seca. Rev bras zootec. 35(1):7-20.

CHACÓN P., BOSCHINI C. 2016. Crecimiento del Ganado Caprino en una finca del Valle Central de Costa Rica. Agronomía Mesoamericana 27(1):159-165.

COAN R.M., REIS R.A., BERNARDES T.F., POIATTI M.L., PEDREIRA M.S., SCHOCKEN R.P. 2005. Composição química e padrão de fermentação de silagens de Tifton 85 com diferentes conteúdos de umidade. ARS VETERINARIA, Jaboticabal, SP: 21:168-174.

DEAN D.B., ADESOGAN A.T., KRUEGER N., LITTELL R.C. 2005. Effect of fibrolytic enzymes on the fermentation characteristics, aerobic stability, and digestibility of Bermudagrass silage. Journal of Dairy Science 88:994-1003.

EVANGELISTA A., DA-LIMA J., BERNARDES T. 2000. Avaliação de algumas características da silagem de gramínea Estrela Roxa (Cynodon nlemfuensis Vanderyst). Rev bras zootec. 29(4):941-946.

FRANSEN S.C., STRUBI F.J. 1998. Relationships among absorbents on the reduction of grass silage effluent and silage quality. Journal of Dairy Science 81:26332644.

GOERING H.K., VAN-SOEST P.J. 1970. Forage fiber analysis (apparatus, reagents, procedures and some applications). Washington DC., Estados Unidos. 20 p.

GONZÁLEZ M.S., VAN-HEURCK L.M., ROMERO F., PEZO D.A., ARGEL P.J. 1996. Producción de leche en pasturas de estrella africana (Cynodon nlemfluensis) solo y asociado con Arachis pintoi o Desmodium ovalifolium. Pastos Tropicales 18(1):2-12.

HERRERA L., VARGAS C.F., BOSCHINI C., CHACÓN A. 2009. Variación bromatológica de la leche de cabras Lamancha alimentadas con diferentes forrajes. Revista Agronomía Mesoamericana 20(2):381-390.

LÓPEZ M., WINGCHING R., ROJAS A. 2009. Características fermentativas y nutricionales del ensilaje de rastrojo de piña (Ananas comosus). Revista Agronomía Costarricense 33(1):1-15.

LUIS L., ESPERANCE M., RAMÍREZ M. 1991. Utilización de aditivos en la conservación de forrajes en forma de ensilaje. I. Aditivos biológicos. Revista Pastos y Forrajes 14(3):185-198.

LUIS L., RAMÍREZ M. 1985. Estudio de los principales grupos de microorganismos presentes en los ensilajes de pasto estrella africana Jamaicano (Cynodon 
nlemfluensis) y su relación con los parámetros bioquímicos. Revista Pastos y Forrajes 8(1):141-155.

MAKONI N.F., BRODERICK D.A., MUCK R.E. 1997. Effect of modified atmospheres on proteolysis and fermentation of ensled alfalfa. Journal of Dairy Science 80:912-920.

MARTÍNEZ A., ARGAMENTERÍA A., DE-LA-ROZA B. 1999. Principios nutritivos y fermentativos de ensilados de hierba en función del tipo de pradera y del aditivo empleado en su elaboración. Poder contaminante de los efluentes generados. Pastos 29(2):171-188.

MARTÍNEZ A., MEGÍAS M.D., HERNÁNDEZ M.R. 1998. Parámetros de contaminación en efluentes de ensilados. Producción ovina y caprina 23:85-88.

MAZA L., VERGARA O., PATERNINA E. 2011. Evaluación química y organoléptica del ensilaje de Maralfalfa (Pennisetum sp.) más yuca fresca (Manihot esculenta). Rev MVZ Córdoba 16(2):2528-2537.

MILLER W.J., CLIFTON C.M. 1965. Relation of dry matter content in ensiled material and other factors to nutrient losses by seepage. Journal of Dairy Science 48:917-923.

MILLER W.J., CLIFTON C.M., CAMERON N.W. 1963. Ensiling characteristics of coastal Bermudagrass harvested at the prehead and full-head stages of growth. Journal of Dairy Science 4:727-732.

MILLER W.J., CLIFTON C.M., FOWLER P.R., CAMERON N.W. 1966. Ensiling characteristics of Tift Sudangrass and Coastal Bermudagrass. Journal of Dairy Science 49:477-485.

MOREIRA F.B., DO-PRADO I.N., CECATO U., YOSHIMI F., DO-NASCIMENTO W.G., SOUZA N.E.D. 2003. Suplementação com sal mineral proteinado para bovinos de corte, em crescimento e terminação, mantidos em pastagem de grama Estrela Roxa (Cynodon plectostachyus Pilger), no inverno. Rev Bras Zootec. 32 (2):449-455.

MÜLHBACH P. 2000. Uso de aditivos para mejorar el ensilaje de los forrajes tropicales. Organización De Las Naciones Unidas Para La Agricultura Y La Alimentación. Uso del ensilaje en el trópico privilegiando opciones para pequeños campesinos. Roma, Italia: FAO. 185 p.

NATIONAL RESEARCH COUNCIL (NRC). 2001. Nutrient requirements of dairy cattle. Sevent Revised Edition. Washington DC., Estados Unidos. 381 p.

OUDE S., DRIEHUIS F., GOTTSCHAL J., SPOELSTRA S. 2000. Los procesos de fermentación del ensilaje y su manipulación. Organización De Las Naciones Unidas Para La Agricultura Y La Alimentación. Uso del ensilaje en el trópico privilegiando opciones para pequeños campesinos. Roma, Italia: FAO. 18 p.

PEREIRA R.C., BANYS V.L., SILVA A.C., PEREIRA R.G.A. 1999. Adição de polpa cítrica peletizada na ensilagem de Capim Elefante (Pennisetum purpureum Schum) cv. Cameroon. R Un Alfenas 5:1147-1152.

QAMAR M. 2009. Effect of molasses and corn as silage additives on the characteristics of Mott Dwarf Elephant grass silage at different fermentation periods. Pakistan Vet J. 29(1):19-23.

QUARESMA J.P.S., ABREU J.G.D., ALMEIDA R.G.D., CABRAL L.D.S., OLIVEIRA M.A.D., RODRIGUES R.C. 2010. Recuperação de matéria seca e composição química de silagens de gramíneas do gênero Cynodon submetidas a períodos de pré-emurchecimento. Ciênc agrotec, Lavras 34(5):1232-1237.

RODRÍGUEZ J., ELIZONDO J. 2012. Consumo, calidad nutricional y digestibilidad aparente de morera (Morus alba) y pasto estrella (Cynodon nlemfluensis) en cabras. Revista Agronomía Costarricense 36(1):13-23.

S.A.S. 1985. Statistical Analysis System. SAS user's guide: Statistics. Versión 5 Ed. Sas Institute Inc. Cary, NC. $373 \mathrm{p}$.

SÁNCHEZ J.M., PIEDRA L., SOTO H. 1998. Calidad nutricional de los forrajes en zonas con niveles bajos de producción de leche, en la zona norte de Costa Rica. Revista Agronomía Costarricense 22(1):69-76.

SANTOS G.T., OLIVEIRA R.L., PETIT H.V., CECATO U. ZEOULA L.M., RIGOLON L.P., DAMASCENO J.C., BRANCO A.F., BETT V. 2000. Short communication: Effect of tannic acid on composition and ruminal degradability of Bermudagrass and alfalfa silages. Journal of Dairy Science 83:20162020.

SANTOS M.V.F., GÓMEZ A.G., PEREA J.M., GARCÍA A., GUIM A., PÉREZ M. 2010. Fatores que afetam o valor nutritivo da silagens de forrageiras tropicais. Arch Zootec. 59 (R):25-43.

SIBANDA S., JINGURA R.M., TOPPS J.H. 1997. The effect of level of inclusion of the legume Desmodium uncinatum and the use of molasses or ground maize as additives on the chemical composition of grassand maize-legume silages. Animal Feed Science Technology 68:295-305.

STEEL R., TORRIE J. 1988. Bioestadística: Principios y procedimientos. México DF, México. 633 p.

TOHNO M., KOBAYASHI H., NOMURA M., KITAHARA M., OHKUMA M., UEGAKI R., CAI Y. 2012. Genotypic and phenotypic characterization of lactic acid bacteria isolated from Italian Ryegrass silage. Animal Science Journal 83:111-120.

UMAÑA R., STAPLES C.R., BATES D.B., WILCOX C.J., MAHANNA W.C. 1991. Effects of a microbial inoculant and (or) sugarcane molasses on the fermentation, aerobic stability, and digestibility of Bermudagrass ensiled at two moisture contents. Journal of Animal Science 69:4588-4601. 
VAN-SOEST P.J., ROBERTSON J.B., LEWIS B.A. 1991. Methods for dietary fiber, neutral detergent fiber and non starch polysaccharides in relation to animal nutrition. Journal of Dairy Science 74(10):3583-3597.

VÁSQUEZ A. 1982. Estudio detallado de los suelos de la estación experimental de ganado lechero El Alto. San José, Costa Rica. 36 p.
VENDRAMINI J.M.B., DESOGAN A.A., SILVEIRA M.L.A., SOLLENBERGER L.E., QUEIROZ O.C.M., ANDERSON W.F. 2010. Nutritive value and fermentation parameters of warm-season grass silage. The Professional Animal Scientist 26:193-200. 
